(C) Facultad de Ciencias Biológicas UNMSM

\title{
Producción de IFN- $\gamma$ en cultivos de linfocitos humanos por efecto de los extractos metanólicos de cuatro ecotipos de Lepidium peruvianum, Chacón (Brassicaceae)
}

\author{
$\gamma$-IFN production in human lymphocytes cultures for effect of the \\ methanolic extracts from four ecotypes of Lepidium peruvianum, Chacón \\ (Brassicaceae)
}

\author{
Libertad Alzamora1, Patricia Galván'1, Evelyn Alvarez¹, Dina Torres', Erasmo \\ Colona ${ }^{1}$, Madeley Aliaga ${ }^{1}$ y Álvaro Marcelo ${ }^{2}$
}

\begin{abstract}
${ }^{1}$ Universidad Nacional Mayor de San Marcos, Facultad de Ciencias Biológicas, Instituto de Investigaciones de Ciencias Biológicas Antonio Raimondi, Laboratorio de Inmunología.

Email Libertad Alzamora: lalzamorag@unmsm.edu.pe ${ }^{2}$ Universidad Nacional Mayor de San Marcos, Facultad de Medicina, Centro de Investigación de Bioquímica y Nutrición.
\end{abstract}

\section{Resumen}

Se estudió la actividad inmunoduladora sobre cultivos de linfocitos $\mathrm{T}$ humanos de sangre periférica. Se evaluó la producción de IFN- $\gamma$ inducida por los extractos metanólicos (EM) de los ecotipos blanco, negro, rojo y morado de Lepidium peruvianum (conocida también como Lepidium meyenii Walp.) maca. Luego de cultivar los linfocitos con los respectivos EM de maca durante 14 horas sólo el EM del ecotipo morado indujo la producción significativa de IFN- $\gamma$ cuantificada mediante Elispot. El extracto metanólico del ecotipo morado de maca posee propiedades inmunoestimuladoras importantes, desencadenando la activación de linfocitos $T$ humanos.

Palabras Clave: Lepidium peruvianum, Lepidium meyenii, ecotipos de maca, maca, inmunomodulación por maca, Interferón- $\gamma$.

\section{Abstract}

The immunomodulatory activity was studied in function of the production of $\gamma$-IFN induced by the methanolic extracts (ME) of the white, black, red and purple ecotypes of Lepidium peruvianum, Chacón (at present Lepidium meyenii Walp.) maca, on cultures of human T lymphocytes obtained of periferic blood. After cultivating the lymphocytes with the respective ME of maca during 14 hours, only the ME of the purple ecotype induced the significant production of IFN- $\gamma$ by Elispot quantified. The methanolic extract of the purple ecotype of maca possesses important immunostimulatory properties triggering the activation of the human $\mathrm{T}$ lymphocytes.

Key words: Lepidium peruvianum, Lepidium meyenii, maca ecotypes, maca, immunomodulation for maca, $\gamma$-Interferon.

\section{Introducción}

Lepidium peruvianum Chacón, (también conocida como Lepidium meyenii Walp.) maca, es una Brassicacea oriunda de los Andes peruanos que crece desde los 3800 hasta los $4500 \mathrm{~m}$ de altitud. Su domesticación y uso en la alimentación data de la época preinca con la cultura Pumpush en la meseta del Bombón, departamento de Junín (Perú) (Chacón, 1997).

El interferón gamma (IFN- $\gamma$ ) es una citoquina importante que ejerce efectos inmunomoduladores sobre células como macrófagos, linfocitos T y B y células NK. Esta citoquina activa macrófagos, potencia la actividad bactericida y tumoricida de las células del sistema inmune, fortalece y mantiene la expresión del complejo mayor de histocompatibilidad en los macrófagos y otras células inmunes y por tanto potencia la actividad de los linfocitos $\mathrm{T}$ (Stites y Terr, 1994).

Una forma de medir la actividad inmunomoduladora de determinados extractos vegetales sobre la respuesta celular de linfocitos in vitro es mediante la detección de la producción de

Nota del Editor: El nombre Lepidium peruvianum Chacón debe ser considerado sinónimo de Lepidium meyenii Walp. (ver Germplasm Resources Information Network, United States Department of Agriculture, Agricultural Research Service, en http:/ /www.ars-grin.gov/cgi-bin/npgs/html/taxon.pl?21767, acceso 08/02/07) preferencias del autor obligan a mantener L. peruvianum Chacón en el texto. citoquinas, detección que puede realizarse usando el inmunoensayo de Elispot. La técnica de ELISPOT es una micro técnica enzimáticacolorimétrica altamente específica y sensible que permite estudiar características específicas de la inmunidad celular, por ejemplo: Respuestas de linfocitos Thelper CD4+ y citotóxicos CD8+. Para este propósito, los linfocitos extraídos de sangre periférica son estimulados con los extractos vegetales y luego son analizados para detectar producción de interferón- $\gamma(\mathrm{IFN}-\gamma)$. Si los linfocitos fueran activados en la muestra, se estimularía la secreción de IFN$\gamma$ y las células serían identificadas usando un sustrato de color (Zuñiga et al., 2006). Esta información es de suma importancia para el tratamiento médico y permitirá que las aplicaciones en la industrialización farmacéutica de la maca tengan sustento científico.

Otros investigadores también han encontrado plantas nativas con propiedades inmunomoduladoras importantes. El 2005 en la Universidad de Ciencia y Tecnología de Hong Kong, Chan et al., encontraron que la fórmula herbal de CKBM compuesta de cinco hierbas medicinales chinas (Panax ginseng, Schisandra chinensis, Fructus crataegi, Ziziphus jujube and Glycine max) suplementado con Saccharomyces cerevisiae procesada, fue capaz de iniciar la secreción de IL6, IL10,TNF- $\alpha$ e IFN- $\gamma$ por células mononucleares de sangre periférica in vitro (Chan et al., 2005). Una planta medicinal con propiedades similares es el Aramu (Petiveria alliacea) cuyo extracto acuoso demostró poseer efecto inmunomodulador aumentando la producción de IFN- $\gamma$ en ratones tratados (Queiroz et al., 2000). 
En el 2004, un grupo taiwanés encontró que el extracto etanólico de Panax ginseng incrementaba la expresión de IL-2, IFN$\gamma$, IL4 e IL-10 por células de bazo de ratones (Larsen et al., 2004). Otro ejemplo de este diseño experimental es el efectuado por un grupo chino que descubrió que el extracto etanólico acuoso de Coriolus versicolor (Yunzhi) indujo una alta producción de IFN- $\gamma$ e IL-8 a las 24 hrs. de incubación de linfocitos de bazo (Ho et al., 2004).

\section{Material y métodos}

Raíces de Lepidium peruvianum de los ecotipos rojo, blanco, negro y morado fueron obtenidas del valle de Pampas, provincia de Tayacaja, departamento de Huancavelica-Perú. Las raíces se cortaron y deshidrataron, se procesaron hasta pulverizarlas. El polvo de maca se maceró en metanol QP. (1:2) durante 10 días. El extracto metanólico (libre del solvente) se llevó a una concentración de $800 \mu \mathrm{g} / \mathrm{ml}$ empleando medio RPMI 1640 (Roswell Park Memorial Institute) estéril como diluyente y se almacenó a $4{ }^{\circ} \mathrm{C}$ hasta su utilización. Todo el procedimiento se realizó en el Laboratorio de Inmunología de la Facultad de Ciencias Biológicas (UNMSM).

Los linfocitos humanos fueron obtenidos a partir de sangre periférica humana de individuos sanos, empleando EDTA como anticoagulante. La sangre se diluyó en buffer fosfato salino (PBS) (1:1), los linfocitos se separaron del resto de células sanguíneas empleando Ficoll-Hypaque ( 2 partes de la sangre diluida y 1 de $\mathrm{FH})$. Se procedió a centrifugar por 30 minutos a $1500 \mathrm{rpm}$. Posteriormente se extrajo el anillo de células (linfocitos y monocitos). Las células se lavaron tres veces con PBS (10 minutos a 1500 rpm). Se eliminó el sobrenadante y se resuspendieron en PBS. Se procedió al recuento en hemocitómetro y se resuspendieron en una concentración de $1 \times 10^{6}$ células $/ \mathrm{ml}$ en el medio de cultivo celular RPMI 1640 (Sigma) enriquecido con 10\% suero bovino fetal (SBF) decomplementado, $1 \%$ estreptomicina, penicilina y $1 \%$ de Solución HEPES. Las células se cultivaron a $37{ }^{\circ} \mathrm{C}$ y $5 \% \mathrm{CO}_{2}$ distribuyendo pocillos para el EM de cada ecotipo $(800 \mu \mathrm{g} / \mathrm{ml})$.

Tabla 1. Se muestran los resultados en promedio de spots obtenidos en la prueba de Elispot, realizada para diferentes ecotipos de Lepidium peruvianum, Chacón; donde se evaluó el efecto de 4 extractos metanólicos de los ecotipos rojo, negro, blanco y morado de maca sobre la activación de linfocitos humanos, se emplearon $1 \times 10^{6}$ células por pocillo, los cultivos se incubaron 14 horas a $37{ }^{\circ} \mathrm{C}$ y $5 \% \mathrm{CO}_{2}$. El control positivo fue fitohemaglutinina y el control negativo medio RPMI 1640. El número de spots obtenidos para el ecotipo morado indica que activó el cultivo de linfocitos lo cual es evidenciable por la secreción de IFN- $\gamma$. Medio RPMI 1640: Roswell Park Memorial Institute

\begin{tabular}{ll} 
Ecotipos & $\begin{array}{l}\text { Promedio } \\
\text { Spots/pocillo } \\
\mathrm{n}=3\end{array}$ \\
\hline Rojo & 2 \\
Negro $/ \mathrm{ml})$ & 1 \\
Blanco & 2 \\
Morado & $>100$ \\
Controles & $>200$ \\
Fitohemaglutinina & \\
$(40 \mu \mathrm{m} / \mathrm{ml})$ & 4 \\
Negativo (RPMI) & \\
\hline
\end{tabular}

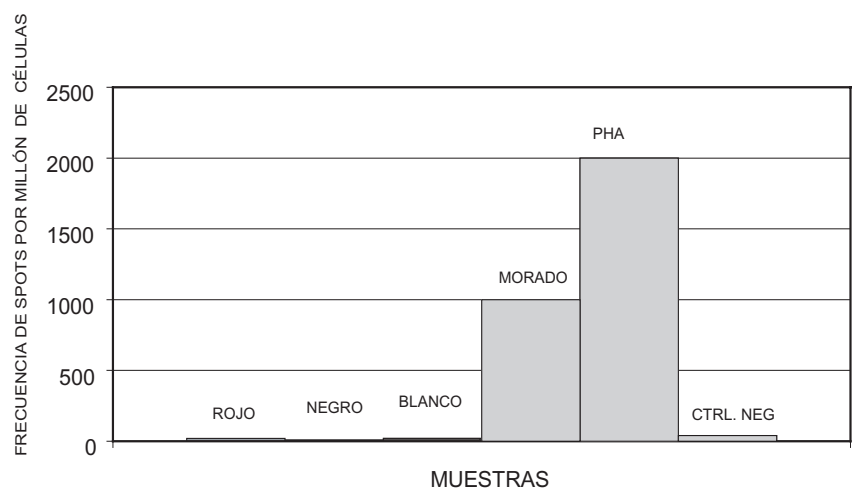

Figura 1. Producción de interferón- $\gamma$ por linfocitos humanos cultivados con extracto metanólico de ecotipos de Lepidium peruvianum Chacón. (maca). Se observan las frecuencias de spots por millón de linfocitos tratados con los extractos metanólicos de los ecotipos rojo, negro, blanco y morado de maca mediante la técnica de Elispot. Se incluyen los controles: positivo Fitohemaglutinina (PHA) y negativo (RPMI 1640: Roswell Park Memorial Institute). Nota: En el estudio realizado no se incluyen intervalos de confianza porque la fórmula aplicada tiene un patrón de lectura estandarizado cuya interpretación es universal.

La prueba de Elispot se desarrolló de la siguiente manera:

Primer día: Se estimuló la placa de Elispot con anti INF- $\gamma$ humano en dilución 1:2000 con PBS estéril (Mabtech) de 12 a 14 horas a $4{ }^{\circ} \mathrm{C}$.

Segundo día: Se bloqueó la placa con el primer anticuerpo, lavando 6 veces con PBS y 1\% SBF decomplementado, luego se descartó el medio de bloqueado y secó el excedente. Se colocó $30 \mu \mathrm{l}$ de medio RPMI 1640 enriquecido como en el procedimiento anterior. En distintos pocillos de la placa se colocó 20 $\mu \mathrm{l}$ del extracto metanólico a una concentración de $800 \mu \mathrm{g} / \mathrm{ml}$ de los 4 ecotipos de L. perwianum (rojo, negro, blanco y morado) por separado; la prueba se hizo por triplicado. Adicionalmente, para cada ecotipo se utilizó 3 pocillos con controles negativos sin extracto de maca (sólo medio RPMI) y 1 pocillo de control positivo con $10 \mu \mathrm{l}$ de una solución de $40 \mu \mathrm{g} /$ $\mathrm{ml}$ de Fitohemaglutinina (PHA). A toda la placa se le añadió $100 \mu \mathrm{l}$ de células y se incubó toda la noche a $37^{\circ} \mathrm{C}$ y $5 \% \mathrm{CO}_{2}$.

Tercer día: Se descartaron las células. Se lavó la placa 6 veces con PBS 1X. Posteriormente se colocó el segundo anticuerpo Anti IFN- $\boldsymbol{\gamma}$ humano biotinilado (Mabtech) (1:2000 en PBS) y se incubó por 60 minutos. Luego se lavó 6 veces con PBS 1X. Se añadió el tercer anticuerpo con estreptavidina (Mabtech) (1:2000 en PBS) y se incubó en oscuridad por 60 minutos. Se añadió la solución de sustrato BCIP y NBT (Biorad) diluida en Tris $1 \mathrm{X}$ pH 9,5 (1:100) se incubó por 15-30 minutos hasta que se observó la aparición de puntos azules llamados «spots» especialmente en el control positivo. Finalmente, se detuvo la reacción descartando el sustrato colocando por 15 minutos $100 \mu \mathrm{l}$ de PBS con $1 \%$ Tween 20. Transcurrido este tiempo se lavó 6 veces con agua corriente y se dejó secar. Los «spots» se contaron con ayuda de un estereoscopio o lupa. Los pocillos positivos fueron aquellos que son mayores o iguales al punto de corte.

El punto de corte se encontró con la siguiente fórmula:

Punto de corte $=3 \mathrm{x}$ Promedio de controles negativos 


\section{Resultados}

El punto de corte obtenido con la fórmula anterior fue de 12, por tanto todos los valores mayores o iguales a 12 spots se consideran positivos para la prueba de Elispot. Para el ecotipo rojo se observó un promedio de 2 spots observados por pocillo, lo cual resultó menor que el valor de punto de corte y por tanto negativo. Para el ecotipo negro de maca se hizo una lectura de 1 spot por pocillo, lo cual también fue negativo. Para el ecotipo blanco se observó un promedio de 2 spots por pocillo. Para el ecotipo morado de maca se obtuvo una lectura de más de 100 spots en promedio por pocillo, mayor al punto de corte y por tanto una respuesta fuertemente positiva para la producción de IFN- $\gamma$ por los linfocitos expuestos a éste extracto. El control positivo PHA dio una lectura mayor de 200 spots por pocillo y los controles negativos de 4 spots en promedio por pocillo. Estos datos también fueron expresados en frecuencias de spots por pocillo (Fig. 1) y se observan en las diferencias marcadas entre la ausencia completa de respuestas significativas de los ecotipos negro, blanco y rojo, respecto a la alta respuesta de INF- $\gamma$ secretado por las células expuestas al ecotipo morado de maca (Tabla 1).

\section{Discusión}

Se han realizado estudios que han demostrado los efectos inmunomoduladores de la maca (Alzamora, 2003), los cuales se deben a la presencia y acción de sus metabolitos secundarios: alcaloides, glucosinolatos, glucotropaeolín y mmetoxiglucotropaelino, macaridina, alcamidas e isocianatos (Piacente et al., 2002; Zhao et al., 2005).

El presente trabajo es el primer reporte que muestra que el ecotipo morado de maca estimula la producción de IFN- $\gamma$ por linfocitos $\mathrm{T}$ humanos, lo cual podría indicar que dicho ecotipo tiene un constituyente químico distinto a los ecotipos rojo, blanco y negro evaluados, consecuentemente modula la inmunidad celular en forma distinta. Aunque aún no se ha identificado cuál de éstos constituyentes químicos es el responsable de la activación de los linfocitos $\mathrm{T}$ en el ecotipo morado, la actividad inmunomoduladora de la maca para el ecotipo amarillo está relacionada con los alcaloides (Alzamora, 2003).

Todavía queda pendiente descubrir cuáles son las cascadas y las moléculas de señalización que están involucradas en este proceso. Con estos resultados podría abrirse toda una gama de aplicaciones terapéuticas en la medicina alternativa. Entre otras aplicaciones, el incremento de IFN- $\gamma$ por el ecotipo morado podría emplearse en el tratamiento del Alzheimer ya que esta citoquina juega un rol crucial en la producción de los péptidos $\beta$-amiloides (Blasko et al., 1999; Valentova y Ulrichova, 2003).

Se concluye que el ecotipo morado de Lepidium perwianum, maca, induce la producción de IFN- $\gamma$ in vitro y por tanto posee acción activadora sobre linfocitos $T$ humanos, propiedades que no evidencian los otros ecotipos evaluados (blanco, rojo y negro). Asimismo, los extractos de ecotipos blanco, negro, y rojo podrían ejercer acciones inmunosupresoras que requieren ser demostradas.

\section{Agradecimientos}

Los autores agradecen el financiamiento otorgado por el Consejo Superior de Investigaciones-UNMSM, Proyecto Nº51001061.

\section{Literatura citada}

Alzamora, L. 2000-2003. Estudio del efecto antitumoral e inmunomodulador del extracto alcaloidal de raíces de Lepidium peruvianum G. Chacón «maca» (Brassicaceae), en ratones. Tesis para optar el Grado Académico de Doctor en Ciencias Biológicas. Unidad de postgrado de la Facultad de Ciencias Biológicas. Universidad Nacional Mayor de San Marcos. 191 pp.

Blasko I, Marx F, Steiner E, Hartmann T, Grubeck-Loebenstein B. 1999. TNF $\alpha$ plus IFN $\gamma$ induce the production of Alzheimer â-amyloid peptides and decrease the secretion of APPs. FASEB J 13: 63-68.

Chacón, G. 1997. La Importancia de Lepidium peruvianum Chacón sp nov. maca en la Alimentación del ser Humano y Animal 2000 años antes y después de Cristo y en el siglo XXI. Servicios Gráficos Romero. Primera Edición. Pp. 8, 22, 6271.

Chan A., E. Yip, L. Yung, H. Pang, S. Luk, S. Pang y Y. Wong 2005. Immuno-regulatory Effects of CKBM on the Activities of Mitogen-Activated Protein Kinases and the Release of Cytokines in THP-1 Monocytic Cells. Biol. Pharm. Bull. 28(9): $1645-1650$.

Ho C., C. Lau, C. Kim, K. Leung, K. Fung, T. Tse, Chan H. y M. Chow. 2004. Differential effect of Coriolus versicolor (Yunzhi) extract on cytokine production by murine lymphocytes in vitro. Int Immunopharmacol. 4 (12):154957.

Larsen M., C. Moser, N. Hoiby, Z. Song y A. Kharazmi. 2004. Ginseng modulates the immune response by induction of interleukin-12 production. APMIS. 112(6):369-73.

Piacente S, V. Carbone, A. Plaza, A. Zampelli y C. Pizza. 2002. Investigation of the tuber constituents of maca (Lepidium meyenii Walp.). J Agric Food Chem. 50(20):5621-5.

Queiroz M., M. Quadros y L. Santos. 2000. Cytokine profile and natural killer cell activity in Listeria monocytogenes infected mice treated orally with Petiveria alliacea extract. Immunopharmacol Immunotoxicol. 22(3): 501-18.

Stites D. y A. Terr. 1994. Inmunología Humana y Básica. 1ra Edición. Manual Moderno. Pp. 145-149

Valentova K. y J. Ulrichova. 2003. Smallanthus sonchifolius and Lepidium meyenii - prospective Andean crops for the prevention of chronic diseases. Biomed Pap Med Fac Univ Palacky Olomouc Czech Repub. 147(2):119-30.

Zhao J, I. Muhammad, D.C. Dunbar, J. Mustafa y I.A. Khan. 2005. New alkamides from maca (Lepidium meyenii). J Agric Food Chem. 53(3): 690-3.

Zúñiga, R., A. Lucchetti, P. Galván, S. Sánchez, J. Peinado, N. Frahm, C. Linde, H. Hewitt, W. H. Hildebrand, D. Montefiori, T. Allen, M. Altfeld, B. D. Walker, J. Sánchez, C. Brander. 2006. Relative Dominance of Gag p24 - Specific Cytotoxic $\mathrm{T}$ Lymphocytes is Associated with Human Inmunodeficiency Virus Control. Journal of Virology 80 (6): 3122-3125. 


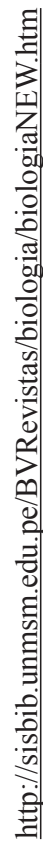

